\title{
Risk factors for lymph node metastasis and prognosis in colorectal neuroendocrine tumours
}

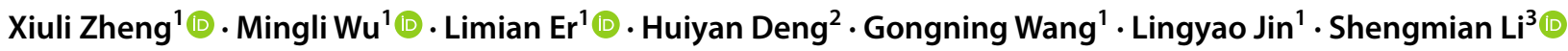

Accepted: 8 December 2021 / Published online: 8 January 2022

(c) The Author(s) 2021

\begin{abstract}
Purpose The detection rate of colorectal neuroendocrine tumours (CR-NETs) is increasing, but their treatment is still controversial. Lymph node metastasis is an important reference index for the selection of treatment. The aim of our study was to investigate the factors associated with lymph node metastasis and prognosis of CR-NETs.

Methods The case characteristics of patients with colorectal neuroendocrine tumours from January 2011 to December 2020 were retrospectively analysed, including age, gender, tumour size, tumour location, lymph node metastasis, pathological grade and follow-up.

Results A total of 195 cases of CR-NETs were included in this study. When $15 \mathrm{~mm}$ was used as the cut-off value, the sensitivity, specificity and area under the curve (AUC) of lymph node metastases were 95.9\%, 95.2\% and 0.986, respectively. Multivariate analysis suggested that tumour size $\geq 15 \mathrm{~mm}$ (OR: 30.517, 95\% CI: 1.250 744.996, $p=0.036$ ) and lymphovascular invasion (OR: 42.796, 95\% CI: 2.882 635.571, $p=0.006$ ) were independent risk factors for lymph node metastasis. Age $\geq 56$ (HR: 7.434, 95\% CI: 1.334 41.443, $p=0.022$ ) and distant metastasis (HR: 24.487, 95\% CI: 5.357 111.940, $p<0.001$ ) were independent prognostic factors in multivariable analyses.

Conclusions When the size of a CR-NET is $\geq 15 \mathrm{~mm}$, the risk of lymph node metastasis is higher, and it is recommended to choose the surgical method carefully. Tumour size and lymphovascular invasion were independent risk factors for lymph node metastasis. Age $\geq 56$ and distant metastasis were independent prognostic factors.
\end{abstract}

Keywords Colorectal neuroendocrine tumour $\cdot$ Lymph node metastasis $\cdot$ Prognosis

\section{Introduction}

Neuroendocrine tumours (NETs) are a kind of tumour with neuroendocrine function and malignant potential. It originates from pheochromo-like cells and has obvious heterogeneity [1]. With the use of colonoscopy, the detection rate of colorectal neuroendocrine tumours (CR-NETs) is increasing

Shengmian Li

shengmianli2013@163.com

1 Department of Endoscopy, The Fourth Hospital of Hebei Medical University, No. 12 Jiankang Road, Chang' an District, Shijiazhuang 050000, Hebei, China

2 Department of Pathology, The Fourth Hospital of Hebei Medical University, No. 12 Jiankang Road, Chang'an District, Shijiazhuang 050000, Hebei, China

3 Department of Gastroenterology, the Fourth Hospital of Hebei Medical University, No. 12 Jiankang Road, Chang' an District, Shijiazhuang 050000, Hebei, China
[2]. The associated risk factors are unknown; a study from Japan has shown higher levels of serum cholesterol and ferritin, metabolic syndrome and family history of cancer as factors that may explain the increasing incidence and prevalence of rectal NET [3]. Tumour sites also vary by race, with the incidence of rectal NETs in the Asian population increasing from 0.2 per 100,000 in 1973 to 0.86 per 100,000 in 2004, which is significantly higher than that in the white population [4]. At the same time, the incidence of CR-NETs is the fastest increasing among all NETs, accounting for $32.6 \%$ of all NETs and becoming the second most common NET in China [5].

It has been reported that before metastasis, the survival rate of CR-NETs is better than that of colorectal adenocarcinoma, and if metastasis occurs, the prognosis is similar to that of adenocarcinoma [6]. Standard resection with locoregional lymphadenectomy is appropriate [7]. Clearance of metastatic lymph nodes is a worthwhile objective that may contribute to long-term survival [8]. However, the choice 


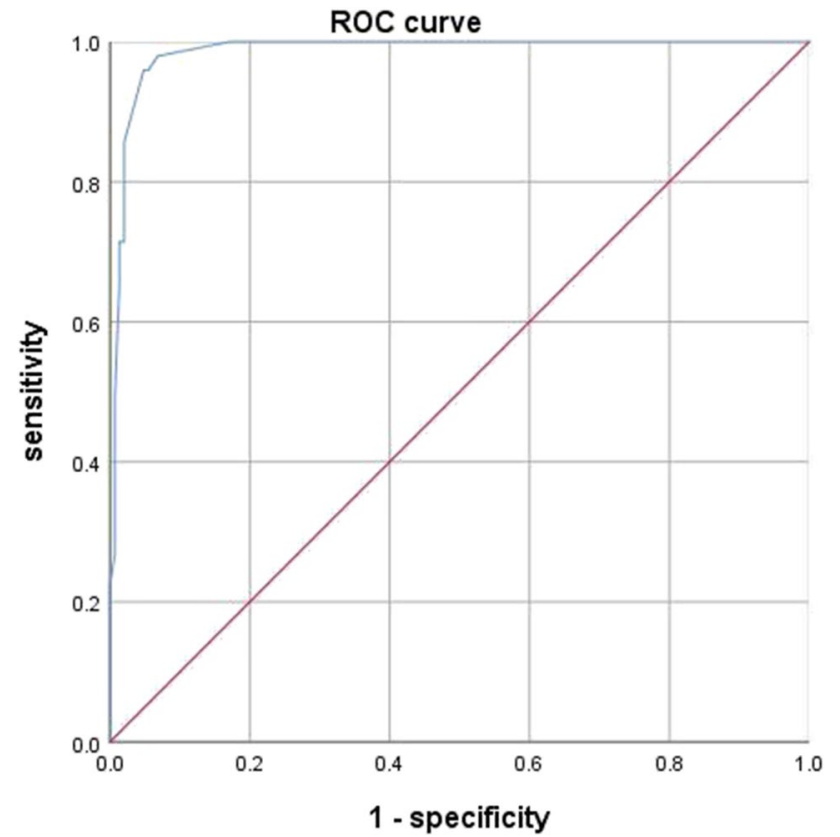

Fig. 1 ROC curve analysis on the relationship between lymph node metastasis and tumour size. When $15 \mathrm{~mm}$ was used as the cut-off value, the sensitivity, specificity and area under the curve (AUC) of lymph node metastasis were $95.9 \%, 95.2 \%$ and 0.986 , respectively

of treatment methods for CR-NETs is still controversial at present [6, 9-12].

Similar to colorectal adenocarcinoma, lymph node metastasis is an important marker of malignancy, and the presence of lymph node metastasis is crucial to the choice of treatment. Reliable lymph node predictors are needed for clinical work [13]. Therefore, the study of lymph node metastasis and its related factors is of great significance for clinical diagnosis and treatment [14]. Studies have shown that there is a close relationship between tumour size and the risk of metastasis [10, 15-19], but it did not come up with an exact value. In this study, we examined the value of tumour size on the risk for lymph node metastasis and the factors associated with prognosis of CR-NETs.

\section{Methods}

\section{Patient population}

This study retrospectively analysed 195 cases of CR-NETs who were diagnosed and treated surgically at the Fourth Hospital of Hebei Medical University from January 2011 to December 2020. We established a retrospective database of patients' medical records, including basic clinical features, pathological reports, and follow-up. The exclusion criteria were as follows: cases complicated with other malignant tumours and cases with incomplete clinical data. Our study was approved by the Ethics Committee of the Fourth Hospital of Hebei Medical University (ID: 2021KS002).

\section{Criteria}

In the case of radical surgery, lymph node metastasis was determined by postoperative pathology. In the cases of endoscopic resection or local resection, computed tomography (CT) or magnetic resonance imaging (MRI) was used preoperatively and during follow-up to assess lymph node metastases. The diagnosis of a metastatic lymph node was based on the following criteria: (1) size criteria: the shortaxis diameter of lymph nodes was greater than $8 \mathrm{~mm}$ for round lymph nodes and greater than $10 \mathrm{~mm}$ for ovoid lymph nodes; (2) morphological abnormalities: irregular contour

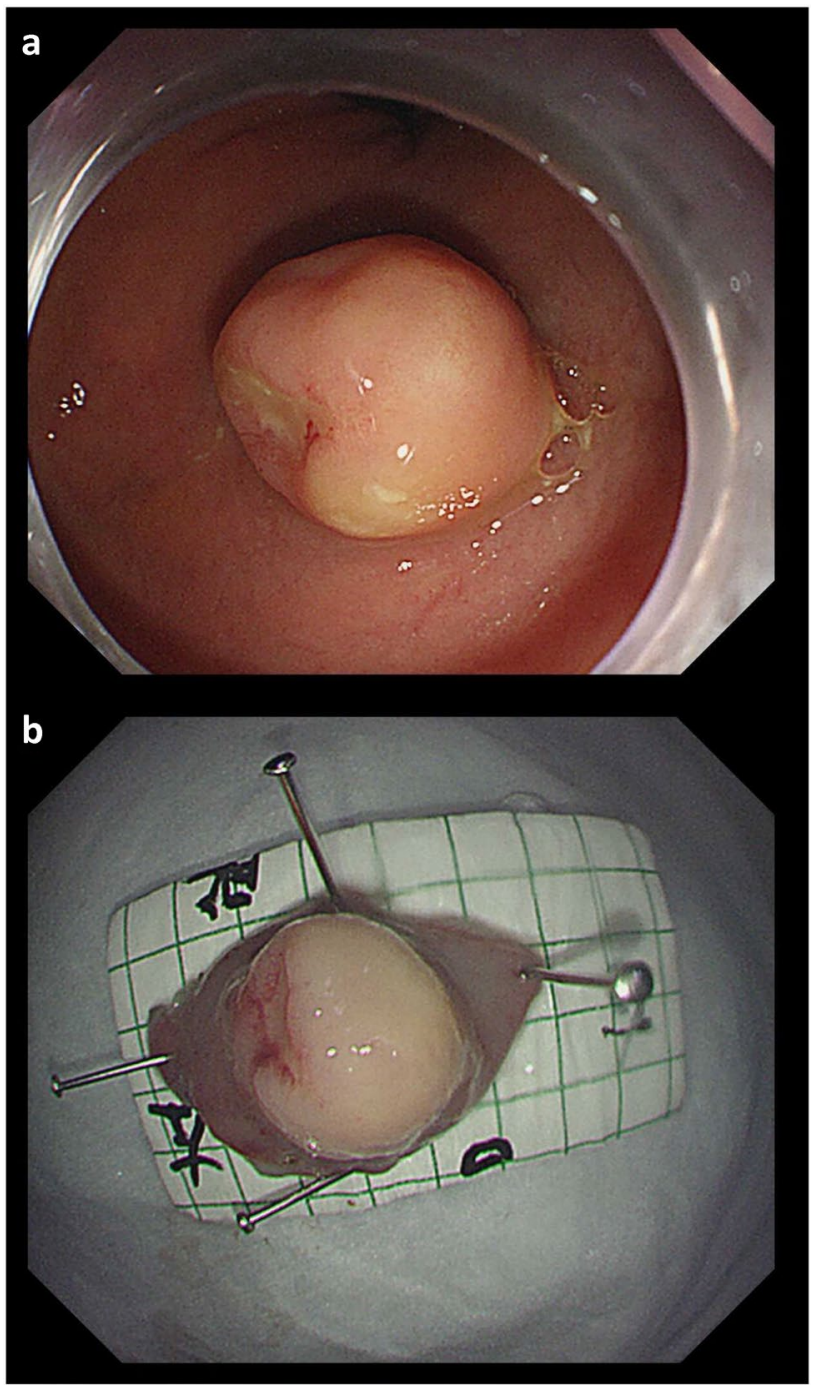

Fig. 2 A NET G1, $12 \mathrm{~mm}$ in size, without lymph node metastasis. a Endoscopic feature of a tumour with central depression in the lower rectum. b The tumour was excised by ESD, and the postoperative specimen was fixed on a calibrated foam plate 


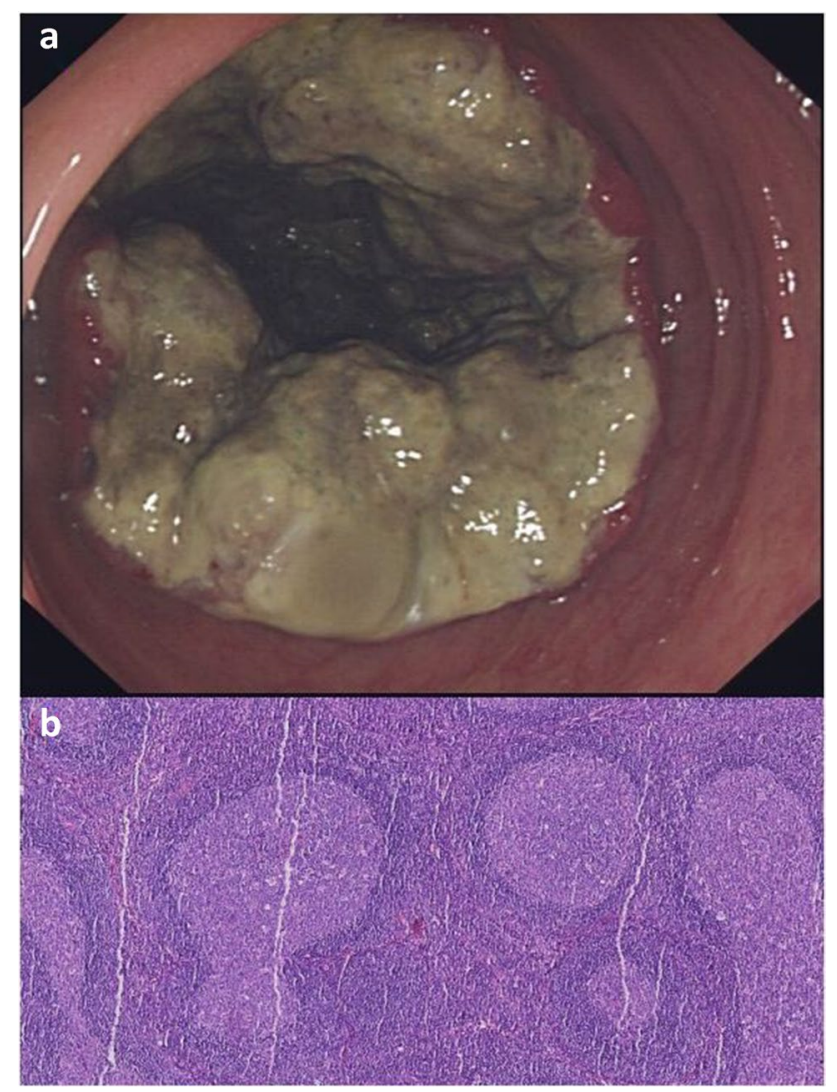

Fig. 3 A NEC, $60 \mathrm{~mm}$ in size, Ki-67 index was $80 \%$. a Protuberant lesions in the transverse colon. $\mathbf{b}$ Lymph node was negative

and margin, unclear border, heterogeneous internal echoes or signal intensity [20-22].

The tumour size was assessed according to the maximum diameter of the tumour reported by pathology, and the tumour with distant metastasis was assessed according to the size of the imaging report.

Tumour stage and pathological diagnosis were defined according to the WHO Classification of Tumours of the Digestive System $5^{\text {th }}$ Edition (2019). Patients were classified as well-differentiated neuroendocrine tumours (NET G1: mitotic rate $<2 / 10 \mathrm{HPF}$ and/or Ki-67 labelling index $<3 \%$; NET G2: mitotic rate 2-20/10 HPF and/or Ki-67 labelling index 3-20\%; NET G3: Ki-67 labelling index $>20 \%$, generally $<60 \%$ ), poorly differentiated neuroendocrine cancer (SCNEC and LCNEC) and mixed neuroendocrine and nonneuroendocrine neoplasms (MiNEN). The higher grade was adopted as Ki-67 labelling index, and mitotic rate figures were inconsistent.

\section{Analysis of tumour size and lymph node metastasis}

To investigate the relationship between tumour size and lymph node metastasis, a receiver operating characteristic

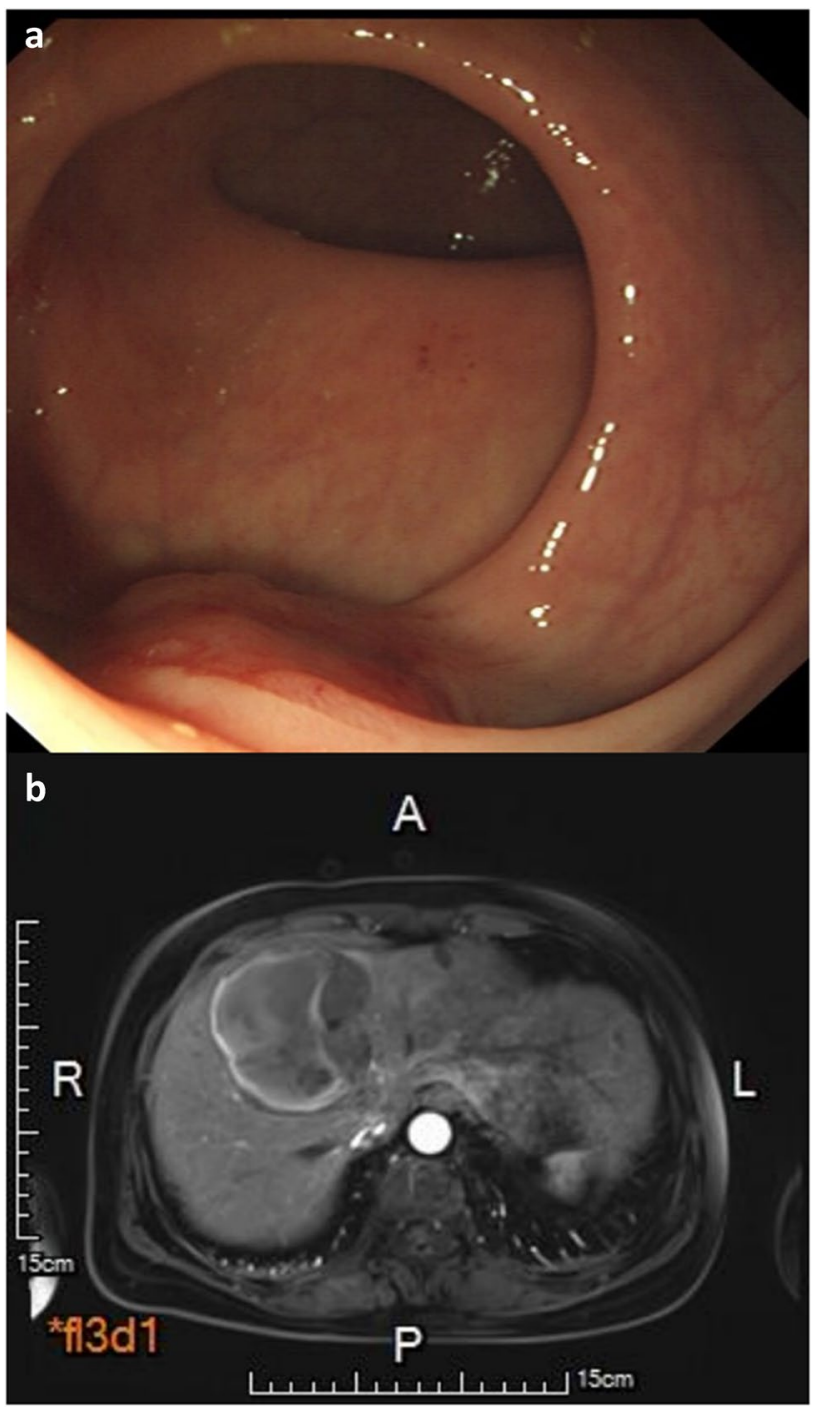

Fig. 4 A NET G2, $20 \mathrm{~mm}$ in size. a Propelled lesion on the left wall about $3-5 \mathrm{~cm}$ from the anus, slightly hyperaemic on the surface mucosa. b MRI indicated multiple liver metastases

(ROC) curve was derived. On the basis of the ROC curve, the tumour size of $15 \mathrm{~mm}$ was defined as an appropriate cutoff level for predicting lymph node metastasis with a high sensitivity rate of $95.9 \%$, specificity rate of $95.2 \%$ and a area under the curve (AUC) of 0.986 (Fig. 1). Patients were stratified using a tumour size cut-off level of $15 \mathrm{~mm}$ to compare the risk of lymph node metastasis.

\section{Follow-up}

Our observation outcome was NETS-related death. The last follow-up was in June 2021. Follow-up was conducted by telephone, outpatient visits or in the hospital. Failure to contact either the patient or his/her family was considered loss to follow-up. 
Table 1 Clinicopathological features of lymph node metastasis in colorectal neuroendocrine tumours

\begin{tabular}{|c|c|c|c|}
\hline Factors & Patients $(n=195)$ & $\begin{array}{l}\text { Lymph node metastasis } \\
(n=49)\end{array}$ & $p$ \\
\hline Gender, $n(\%)$ & & & 0.866 \\
\hline $\begin{array}{l}\text { Male } \\
\text { Female }\end{array}$ & $\begin{array}{l}120 \\
75\end{array}$ & $\begin{array}{l}31(25.8 \%) \\
18(24.0 \%)\end{array}$ & \\
\hline Age, years, $n(\%)$ & & & $<0.001$ \\
\hline $\begin{array}{l}\text { Median (range) } \\
<56 \\
\geq 56\end{array}$ & $\begin{array}{l}56(20-76) \\
88 \\
107\end{array}$ & $\begin{array}{l}11(12.5 \%) \\
38(35.5 \%)\end{array}$ & \\
\hline Tumor size, mm, $n(\%)$ & & & $<0.001$ \\
\hline $\begin{array}{l}<15 \\
\geq 15\end{array}$ & $\begin{array}{l}141 \\
54\end{array}$ & $\begin{array}{l}2(1.40 \%) \\
47(87.0 \%)\end{array}$ & \\
\hline Tumor location, $n(\%)$ & & & $<0.001$ \\
\hline $\begin{array}{l}\text { Rectum } \\
\text { Colon }\end{array}$ & $\begin{array}{l}164 \\
31\end{array}$ & $\begin{array}{l}23(14.0 \%) \\
26(83.9 \%)\end{array}$ & \\
\hline Lymphovascular invasion, $n(\%)$ & & & $<0.001$ \\
\hline $\begin{array}{l}\text { Negative } \\
\text { Positive }\end{array}$ & $\begin{array}{l}154 \\
41\end{array}$ & $\begin{array}{l}14(9.10 \%) \\
35(85.37 \%)\end{array}$ & \\
\hline Muscularis propria invasion, $n(\%)$ & & & $<0.001$ \\
\hline $\begin{array}{l}\text { Negative } \\
\text { Positive }\end{array}$ & $\begin{array}{l}145 \\
50\end{array}$ & $\begin{array}{l}3(2.1 \%) \\
46(92.0 \%)\end{array}$ & \\
\hline Ki 67 index, $n(\%)$ & & & $<0.001$ \\
\hline $\begin{array}{l}\leq 20 \% \\
>20 \%\end{array}$ & $\begin{array}{l}157 \\
38\end{array}$ & $\begin{array}{l}13(8.3 \%) \\
36(94.7 \%)\end{array}$ & \\
\hline $\mathrm{CgA}, n(\%)$ & & & $<0.001$ \\
\hline $\begin{array}{l}\text { Negative } \\
\text { Positive }\end{array}$ & $\begin{array}{l}135 \\
60\end{array}$ & $\begin{array}{l}10(7.40 \%) \\
39(65.0 \%)\end{array}$ & \\
\hline Syn, $n(\%)$ & & & 0.642 \\
\hline $\begin{array}{l}\text { Negative } \\
\text { Positive }\end{array}$ & $\begin{array}{l}6 \\
189\end{array}$ & $\begin{array}{l}2(33.3 \%) \\
47(24.9 \%)\end{array}$ & \\
\hline
\end{tabular}

\section{Statistical analysis}

Continuous variables are presented as the mean with standard deviation (SD) or the median with range and were evaluated by the $t$-test. Categorical data are expressed as numbers and percentages, and analysis was conducted through a chisquare test. The predictors of lymph node metastasis were analysed by binary logistic regression. The Kaplan-Meier method was used to plot survival curves. Survival analyses were compared using Cox proportional hazard regression. Double-tailed $p$ values were used for all statistical tests, and 0.05 was set as the significance threshold. Statistical analysis was performed using IBM SPSS Statistics v.25.0.0 (IBM Corp, New York). The survival curves were produced by GraphPad Prism 8.0.1 (GraphPad Software Inc., San Diego).

\section{Results}

A total of 195 cases of CR-NETs were included in this study, including 31 cases of colon tumour and 164 cases of rectum tumour. The male-to-female ratio was 120:75, the median age was 56 years and the tumour size was $15.52 \pm 17.41 \mathrm{~mm}$. Among them, 111 patients underwent endoscopic resection (Fig. 2), 32 patients underwent transanal endoscopic
Table 2 Multivariate analysis of factors for lymph node metastasis

\begin{tabular}{llll}
\hline Factors & OR & $95 \%$ CI & $p$ \\
\hline $\begin{array}{l}\text { Age, years } \\
\quad<56\end{array}$ & 1 & Reference & 0.883 \\
$\quad \geq 56$ & 1.156 & $0.168 \sim 7.948$ & \\
Tumor size, mm & & & 0.032 \\
$\quad<15$ & 1 & Reference & \\
$\quad \geq 15$ & 34.295 & $1.354 \sim 868.933$ & \\
Tumor location & & & 0.856 \\
$\quad$ Rectum & 1 & Reference & \\
$\quad$ Colon & 0.788 & $0.059 \sim 10.434$ & \\
Lymphovascular invasion & & & 0.011 \\
$\quad$ Negative & 1 & Reference & \\
$\quad$ Positive & 24.994 & $2.121 \sim 294.510$ & \\
Muscularis propria invasion & & & 0.072 \\
$\quad$ Negative & 1 & Reference & \\
$\quad$ Positive & 17.856 & $0.769 \sim 414.536$ & \\
Ki 67 index & & & 0.767 \\
$\quad \leq 20 \%$ & 1 & Reference & \\
$>20 \%$ & 0.642 & $0.034 \sim 12.134$ & \\
CgA & & & 0.066 \\
$\quad$ Negative & 1 & Reference & \\
$\quad$ Positive & 6.236 & $0.886 \sim 43.917$ & \\
\hline
\end{tabular}

OR odds ratio, $95 \%$ CI 95\% confidence interval 
Table 3 Univariable and multivariable Cox proportional hazard regression analyses of OS

\begin{tabular}{|c|c|c|c|c|c|c|}
\hline \multirow[t]{2}{*}{ Factors } & \multicolumn{3}{|c|}{ Univariable } & \multicolumn{3}{|c|}{ Multivariable } \\
\hline & HR & $95 \% \mathrm{CI}$ & $p$ & HR & $95 \% \mathrm{CI}$ & $p$ \\
\hline \multicolumn{7}{|l|}{ Gender } \\
\hline Male & 1 & Reference & & & & \\
\hline Female & 0.994 & $0.439 \sim 2.251$ & 0.988 & & & \\
\hline \multicolumn{7}{|l|}{ Age, years } \\
\hline$<56$ & 1 & Reference & & 1 & Reference & \\
\hline$\geq 56$ & 5.074 & $1.511 \sim 17.036$ & 0.009 & 7.434 & $1.334 \sim 41.443$ & 0.022 \\
\hline \multicolumn{7}{|c|}{ Tumor size, mm } \\
\hline$<15$ & 1 & Reference & & 1 & Reference & \\
\hline$\geq 15$ & 347.984 & $4.347 \sim 27,855.655$ & 0.009 & $30,372.9$ & $0.00 \sim 1.029 \mathrm{E}+74$ & 0.899 \\
\hline \multicolumn{7}{|c|}{ Tumor location } \\
\hline Rectum & 1 & Reference & & 1 & Reference & \\
\hline Colon & 10.296 & $4.482 \sim 23.651$ & $<0.001$ & 1.211 & $0.455 \sim 3.221$ & 0.702 \\
\hline \multicolumn{7}{|c|}{ Lymphovascular invasion } \\
\hline Negative & 1 & Reference & & 1 & Reference & \\
\hline Positive & 1.149 & $1.020 \sim 1.294$ & 0.022 & 2.053 & $0.430 \sim 9.800$ & 0.367 \\
\hline \multicolumn{7}{|c|}{ Muscularis propria invasion } \\
\hline Negative & 1 & Reference & & 1 & Reference & \\
\hline Positive & 79.614 & $10.738 \sim 590.269$ & $<0.001$ & 0.343 & $0.016 \sim 7.344$ & 0.493 \\
\hline \multicolumn{7}{|c|}{ Ki 67 index } \\
\hline$\leq 20 \%$ & 1 & Reference & & 1 & Reference & \\
\hline$>20 \%$ & 53.017 & $12.376 \sim 227.117$ & $<0.001$ & 1.798 & $0.212 \sim 15.264$ & 0.591 \\
\hline \multicolumn{7}{|l|}{$\mathrm{CgA}$} \\
\hline Negative & 1 & Reference & & 1 & Reference & \\
\hline Positive & 224.159 & $4.624 \sim 10,867.568$ & 0.006 & $12,536.2$ & $0.000 \sim 1.031 \mathrm{E}+74$ & 0.909 \\
\hline \multicolumn{7}{|l|}{ Syn } \\
\hline Negative & 1 & Reference & & & & \\
\hline Positive & 22.104 & $0.010 \sim 48,428.080$ & 0.43 & & & \\
\hline \multicolumn{7}{|c|}{ Lymph node metastasis } \\
\hline Negative & 1 & Reference & & 1 & Reference & \\
\hline Positive & 578.679 & $3.338 \sim 100,330.303$ & 0.016 & 10,529 & $0.000 \sim 2.823 \mathrm{E}+70$ & 0.906 \\
\hline \multicolumn{7}{|c|}{ Distant metastasis } \\
\hline Negative & 1 & Reference & & 1 & Reference & \\
\hline Positive & 54.618 & $18.032 \sim 165.430$ & $<0.001$ & 24.487 & $5.357 \sim 111.940$ & $<0.001$ \\
\hline
\end{tabular}

OS overall survival, $H R$ hazard ratio, $95 \%$ CI 95\% confidence interval

\section{Distant metastasis}

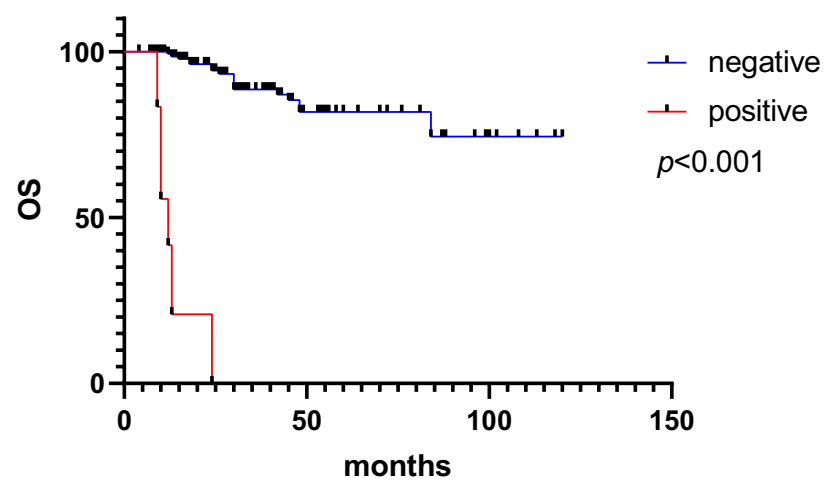

Age

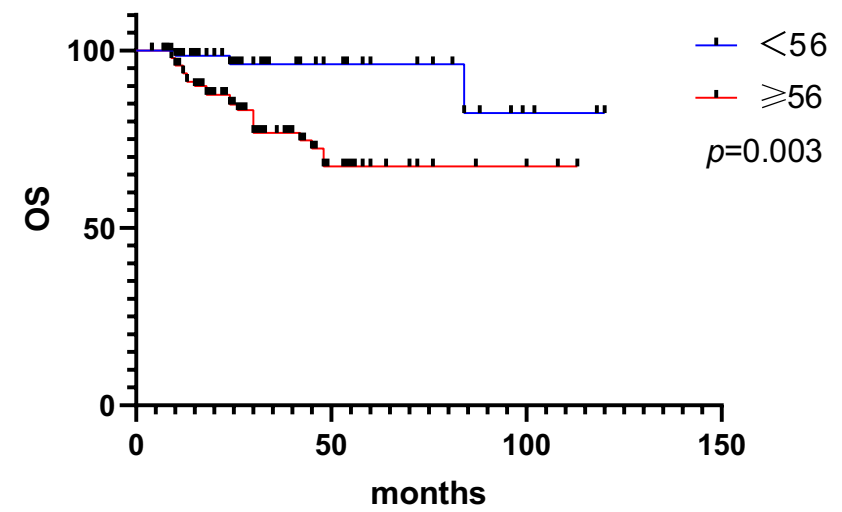

Fig. 5 The survival curves according to distant metastasis

Fig. 6 The survival curves according to age 


\section{Lymph node metastasis}

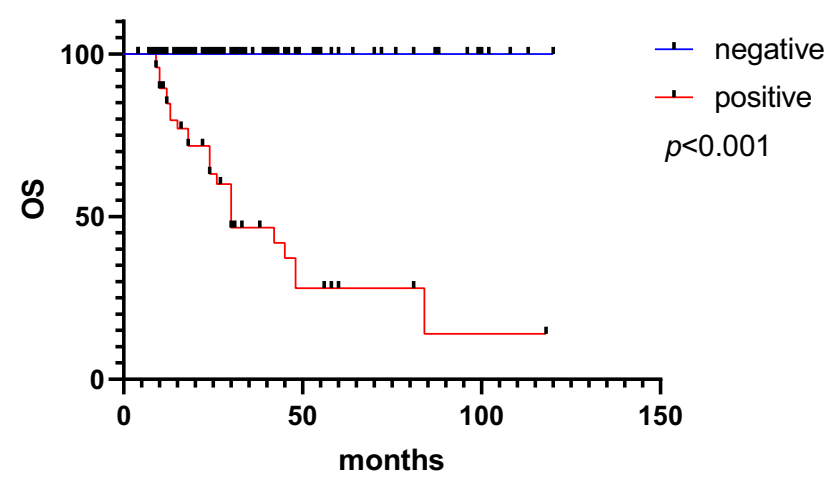

Fig. 7 The survival curves according to lymph node metastasis

microsurgery (TEM) resection, 40 patients underwent radical surgical resection (Fig. 3) and 12 patients underwent palliative surgical resection (Fig. 4). Distant metastasis occurred in 12 cases.

Of the 195 CR-NETs, 49 cases had lymph node metastasis, with an overall metastatic rate of $25.13 \%$ (49/195). Clinicopathological features of lymph node metastasis in CR-NETs are shown in Table 1. The study showed that the differences in lymph node metastasis rate were statistically significance in age $(p<0.001)$, tumour size $(p<0.001)$, tumour location $(p<0.001)$, lymphovascular invasion $(p<0.001)$, muscularis propria invasion $(p<0.001)$, Ki 67 index $(p<0.001)$ and $\mathrm{CgA}(p<0.001)$. Multivariate analysis (Table 2) suggested that tumour size $\geq 15 \mathrm{~mm}$ (OR: 30.517 , 95\% CI: $1.250 \sim 744.996, p=0.036)$ and lymphovascular invasion (OR: 42.796, 95\% CI: 2.882 635.571, $p=0.006$ ) were independent risk factors for lymph node metastasis.

Of the 195 cases, 21 patients were lost to follow-up, 174 patients were included in the follow-up process and 25 patients died of tumour-related causes. The follow-up time ranged from 6 to 118 months, with a median followup time of 28 months, and local recurrence occurred in 2 cases of ESD-resected lesions. Patient age $(p=0.009)$, tumour size $(p=0.009)$, tumour location $(p<0.001)$, lymphovascular invasion $(p=0.022)$, muscularis propria invasion $(p<0.001), \mathrm{Ki}-67$ index $(p<0.001), \mathrm{CgA}(p=0.006)$, lymph node metastasis $(p=0.016)$ and distant metastasis $(p<0.001)$ were all associated with prognosis in univariable analyses. Age $\geq 56$ (HR: 7.434, 95\% CI: $1.334 \sim 41.443$, $p=0.022$ ) and distant metastasis (HR: $24.487,95 \% \mathrm{CI}$ : $5.357 \sim 111.940, p<0.001)$ were independent prognostic factors in multivariable analyses. Univariable and multivariable Cox proportional hazard regression analyses of OS are shown in Table 3. The survival curves according to distant metastasis, age and lymph node metastasis are shown in Figs. 5, 6 and 7. The 1-year and 5-year survival rates without distant metastasis were $99.3 \%$ and $94.3 \%$, respectively. The 1-year and 5-year survival rates with distant metastasis were $41.7 \%$ and 0 , respectively. The 1 -year and 5 -year survival rates were $98.5 \%$ and $82.4 \%$ for those under 56 years of age, $95.8 \%$ and $67.4 \%$ for those $\geq 56$ years of age. The 1 -year and 5-year survival rates without lymph node metastasis were $100 \%$ and $100 \%$, respectively. The 1-year and 5-year survival rates with lymph node metastasis were $84.7 \%$ and $28 \%$, respectively.

\section{Discussion}

This study examined the risk factors for lymph node metastasis of CR-NETS, particularly the relationship between tumour size and lymph node metastasis, and derived a new cut-off value (tumour size $=15 \mathrm{~mm}$ ). Furthermore, it is confirmed that in CR-NETs, size $\geq 15 \mathrm{~mm}$ and lymphovascular invasion were independent risk factors for lymph node metastasis, suggesting that these patients should be highly suspected of having lymph node metastasis and should consider the condition comprehensively and carefully select the surgical plan. Meanwhile, age $\geq 56$ and distant metastasis were independent prognostic factors.

The NCCN consensus suggests that the size of the primary tumour should be taken as the main criteria for the selection of treatment and monitoring strategies [14]. Endoscopic resection or local resection is recommended for lesions less than $1 \mathrm{~cm}$, and surgical resection is recommended for lesions greater than $2 \mathrm{~cm}$. CR-NETs in between have no clear treatment recommendations. At present, the treatment strategy for tumours between 10 and $19 \mathrm{~mm}$ is still controversial [6, 9-11]. Some people recommend radical surgical resection, while others recommend endoscopic resection or local resection; the key factor is whether there is lymph node involvement.

Many past studies have shown a close relationship between tumour size and the risk of metastasis. The reported rate of lymph node metastasis is $1-7 \%$ when tumours are smaller than $10 \mathrm{~mm}[6,18,23]$. Konishi et al. found that R-NETs with a diameter of 11-20 mm had a higher metastatic potential, with a lymph node metastasis rate of $40 \%$ [6]. Soga showed that the metastatic rate for 11-20-mm tumours was 30\% [18]. But no exact value was given for grouping tumour sizes. In our study, when $15 \mathrm{~mm}$ is the cut-off value, the sensitivity, specificity and AUC of lymph node metastasis were 95.9\%, 95.2\% and 0.986, respectively. Perhaps we can distinguish tumour size by $15 \mathrm{~mm}$. In our study, when tumour $\geq 15 \mathrm{~mm}$, the lymph node metastasis rate was $93.0 \%$, much higher than $5.9 \%$ in the $<15$-mm group. Moreover, tumour size $\geq 15 \mathrm{~mm}$ was an independent risk factor for lymph node metastasis. For tumours $\geq 15 \mathrm{~mm}$, a higher lymph node metastasis rate should be considered, and the surgical plan should be carefully selected. The research results of Park are consistent with ours [24]. 
Lymphovascular invasion was an independent risk factor for lymph node metastasis. Some studies were consistent with our conclusions. Lymphovascular invasion should be treated seriously in patients with local resection. In Kang's study [25], he pointed out that the incidence of lymphatic vascular invasion of small rectal NET was $21.8 \%$, and its occurrence was related to tumour size, and greater than $5 \mathrm{~mm}$ was a risk factor for lymphatic vascular invasion. In our study, among 111 cases of endoscopic resection, 6 cases had lymphatic vascular infiltration, and one of them underwent additional surgery without lymph node metastasis. The rest were followed up, and no recurrence or metastasis was found at present, with the longest follow-up period of 6 years. For small rectal NET with lymphatic vascular invasion which resected by endoscopy, Kang et al. recommends a longer follow-up [25].

In our study, age $\geq 56$ and distant metastasis were independent prognostic factors. For older patients, it may be due to poor physical fitness, not being able to tolerate the side effects of surgery, drugs and others. Once the tumour has distant metastasis, the patient's OS is significantly shortened and the prognosis is poor. Even if the primary tumour is removed, the treatment for metastasis will increase the burden on the body; coupled with the double burden of the tumour, the survival will be significantly shortened. At the same time, tumour size, location, lymphovascular invasion, muscularis propria invasion, Ki 67 index, $\mathrm{CgA}$ and lymph node metastasis were important prognostic factors. $\mathrm{Yu}$ et al. study confirmed that tumour size was an independent prognostic factor [26]. Kim et al. work suggested that CgA expression was an independent predictor of prognosis [27]. Wu et al. study confirmed that age, tumour location, lymph node status and positive level of $\mathrm{CgA}$ were independent risk factors affecting prognosis [16]. Therefore, the prognosis of colorectal neuroendocrine tumour cannot be determined by any one factor and needs to be considered comprehensively, especially the poor prognosis with advanced age and distant metastasis.

In this study, 164 NETs occurred in the rectum and 31 in the colon, and most of the tumours in the colon were poorly differentiated. Colonic NETs are a rare malignancy, with an incidence rate of 1 to 2 per million, accounting for less than $1 \%$ of all colonic malignancies [28]. With the use of colonoscopy, an increasing number of colorectal tumours have been identified, but well-differentiated colonic NETs are rare. Here, the rate of lymph node metastasis for colonic NET was $83.9 \%$, which was significantly higher than the $14.0 \%$ rate in the rectum, and the prognosis was poor. So why does this happen? Is it because colonoscopy is insensitive to lesions in the colon? Or is it due to the rapid development of colonic lesions, short window period and high degree of malignancy? These problems need to be researched in future studies.
We note that the predictors of lymph node metastasis in colorectal neuroendocrine tumours and adenocarcinoma are not identical. Brodsky et al. study confirmed that tumour size was not significant a predictive feature for lymph node metastasis in early rectal cancer [29]. For early colorectal adenocarcinoma, the depth of invasion and tumour budding should be considered more. In Bosch et al. research, submucosal invasion $\geq 1 \mathrm{~mm}$ and budding were the strongest independent predictors of lymph node metastasis in early colorectal cancer [30].

Of course, there are some limitations to our study. First, this is a single-centre retrospective study, and there may be bias in the selection of cases. Second, the sample size was not large enough. Third, lymph node evaluation should mainly be based on pathological evaluation after radical resection. However, for local resection cases, we cannot conduct a pathological evaluation but can only conduct imaging evaluation, which may have some errors. Therefore, a large prospective randomized controlled trial is needed to investigate the selection of treatment options for CR-NETs.

In conclusion, when the size of a CR-NET is $\geq 15 \mathrm{~mm}$, the risk of lymph node metastasis is higher, and it is recommended to choose the surgical method carefully. Tumour size and lymphovascular invasion were independent risk factors for lymph node metastasis. Meanwhile, age $\geq 56$ and distant metastasis were independent prognostic factors.

Author contribution Study concept and design: Xiuli Zheng, Mingli Wu, Shengmian Li. Acquisition of data: Xiuli Zheng, Limian Er. Analysis and interpretation of data: Xiuli Zheng, Huiyan Deng, Gongning Wang, Lingyao Jin. Drafting of the manuscript: Xiuli Zheng. Critical revision of manuscript: Shengmian Li, Mingli Wu. All authors read and approved the final manuscript.

Funding This project was supported by Bethune Charitable Foundation (BCF-NH-ZL-20201119-007).

\section{Declarations}

Ethics approval This project was approved by the Ethics Committee of the Fourth Hospital of Hebei Medical University (ID: 2021KS002).

Conflict of interest The authors declare no competing interests.

Open Access This article is licensed under a Creative Commons Attribution 4.0 International License, which permits use, sharing, adaptation, distribution and reproduction in any medium or format, as long as you give appropriate credit to the original author(s) and the source, provide a link to the Creative Commons licence, and indicate if changes were made. The images or other third party material in this article are included in the article's Creative Commons licence, unless indicated otherwise in a credit line to the material. If material is not included in the article's Creative Commons licence and your intended use is not permitted by statutory regulation or exceeds the permitted use, you will need to obtain permission directly from the copyright holder. To view a copy of this licence, visit http://creativecommons.org/licenses/by/4.0/. 


\section{References}

1. Yao JC, Hassan M, Phan A, Dagohoy C, Leary C, Mares JE et al (2008) One hundred years after carcinoid: epidemiology of and prognostic factors for neuroendocrine tumors in 35,825 cases in the United States. J Clin Oncol 26(18):3063-3072. https://doi.org/ 10.1200/JCO.2007.15.4377

2. Folkert IW, Sinnamon AJ, Concors SJ, Bennett BJ, Fraker DL, Mahmoud NN et al (2020) Grade is a dominant risk factor for metastasis in patients with rectal neuroendocrine tumors. Ann Surg Oncol 27(3):855-863. https://doi.org/10.1245/s10434-019-07848-0

3. Pyo JH, Hong SN, Min BH, Lee JH, Chang DK, Rhee PL et al (2016) Evaluation of the risk factors associated with rectal neuroendocrine tumors: a big data analytic study from a health screening center. J Gastroenterol 51(12):1112-1121. https://doi. org/10.1007/s00535-016-1198-9

4. Wu ZJ, Zhou MY (2020) Progress in diagnosis and treatment of rectal neuroendocrine neoplasms. Zhonghua zhong liu za zhi [Chin J Oncol] 42(6):438-444

5. Fan J, Zhang Y, Shi S, Chen Y, Yuan X, Jiang L et al (2017) A nation-wide retrospective epidemiological study of gastroenteropancreatic neuroendocrine neoplasms in china. Oncotarget 8(42):71699-71708. https://doi.org/10.18632/oncotarget.17599

6. Konishi T, Watanabe T, Kishimoto J, Kotake K, Muto T, Nagawa $\mathrm{H}$ et al (2007) Prognosis and risk factors of metastasis in colorectal carcinoids: results of a nationwide registry over 15 years. Gut 56(6):863-868. https://doi.org/10.1136/gut.2006.109157

7. Bernick PE, Klimstra DS, Shia J, Minsky B, Saltz L, Shi W et al (2004) Neuroendocrine carcinomas of the colon and rectum. Dis Colon Rectum 47(2):163-169. https://doi.org/10.1007/s10350-003-0038-1

8. Ramage JK, Ahmed A, Ardill J, Bax N, Breen DJ, Caplin ME et al (2011) Guidelines for the management of gastroenteropancreatic neuroendocrine (including carcinoid) tumours (NETs). Gut 61(1):6-32. https://doi.org/10.1136/gutjnl-2011-300831

9. Onozato Y, Kakizaki S, Iizuka H, Sohara N, Mori M, Itoh H (2010) Endoscopic treatment of rectal carcinoid tumors. Dis Colon Rectum 53(2):169-176. https://doi.org/10.1007/DCR. 0b013e3181b9db7b

10. Tsukamoto S, Fujita S, Yamaguchi T, Yamamoto S, Akasu T, Moriya $Y$ et al (2008) Clinicopathological characteristics and prognosis of rectal well-differentiated neuroendocrine tumors. Int J Colorectal Dis 23(11):1109-1113. https://doi.org/10.1007/s00384-008-0505-1

11. Gleeson FC, Levy MJ, Dozois EJ, Larson DW, Wong Kee Song LM, Boardman LA (2014) Endoscopically identified well-differentiated rectal carcinoid tumors: impact of tumor size on the natural history and outcomes. Gastrointest Endosc 80(1):144-151. https://doi.org/10.1016/j.gie.2013.11.031

12. Heah SM, Eu KW, Ooi BS, Ho YH, Seow-Choen F (2001) Tumor size is irrelevant in predicting malignant potential of carcinoid tumors of the rectum. Tech Coloproctol 5(2):73-77. https://doi. org/10.1007/s101510170002

13. Sugimoto S, Hotta K, Shimoda T, Imai K, Yamaguchi Y, Nakajima T et al (2016) The Ki-67 labeling index and lymphatic/venous permeation predict the metastatic potential of rectal neuroendocrine tumors. Surg Endosc 30(10):4239-4248. https://doi.org/10.1007/ s00464-015-4735-3

14. Ramage JK, De Herder WW, Delle FG, Ferolla P, Ferone D, Ito T et al (2016) ENETS consensus guidelines update for colorectal neuroendocrine neoplasms. Neuroendocrinology 103(2):139-143. https://doi.org/10.1159/000443166

15. Li P, Wu F, Zhao H, Dou L, Wang Y, Guo C et al (2015) Analysis of the factors affecting lymph node metastasis and the prognosis of rectal neuroendocrine tumors. Int J Clin Exp Pathol 8(10):13331-13338

16. Wu Z, Wang Z, Zheng Z, Bi J, Wang X, Feng Q (2020) Risk factors for lymph node metastasis and survival outcomes in colorectal neuroendocrine tumors. Cancer Manag Res 12:7151-7164. https:// doi.org/10.2147/CMAR.S256723

17. Zhou X, Xie H, Xie L, Li J, Fu W (2013) Factors associated with lymph node metastasis in radically resected rectal carcinoids: a systematic review and meta-analysis. J Gastrointest Surg 17(9):1689-1697. https://doi.org/10.1007/s11605-013-2249-7

18. Soga J (1997) Carcinoids of the rectum: an evaluation of 1271 reported cases. Surgery today (Tokyo, Japan) 27(2):112-119. https://doi.org/10.1007/BF02385898

19. Schindl M, Niederle B, Hafner M, Teleky B, Langle F, Kaserer K et al (1998) Stage-dependent therapy of rectal carcinoid tumors. World J Surg 22(6):628-633, 634. https://doi.org/10.1007/s002689900445

20. Al-Sukhni E, Milot L, Fruitman M, Beyene J, Victor JC, Schmocker S et al (2012) Diagnostic accuracy of MRI for assessment of $\mathrm{T}$ category, lymph node metastases, and circumferential resection margin involvement in patients with rectal cancer: a systematic review and meta-analysis. Ann Surg Oncol 19(7):22122223. https://doi.org/10.1245/s10434-011-2210-5

21. Brown G, Richards R, Bourne MW, Newcombe RG, Radcliffe AG (2003) Morphologic predictors of lymph node status in rectal cancer with use of high-spatial-resolution MR imaging with histopathologic comparison1. Radiology 227:371-377

22. Zhang G, Cai Y, Xu G (2016) Diagnostic accuracy of MRI for assessment of $\mathrm{T}$ category and circumferential resection margin involvement in patients with rectal cancer. Dis Colon Rectum 59(8):789-799. https://doi.org/10.1097/DCR.0000000000000611

23. Duan X, Zhao M, Zhang S, Xu Z, Mi L, Shi J et al (2020) Effects of tumor distance from anal verge on survival outcomes for rectal NENs and lymphatic metastasis risk score for colorectal NENs. Int J Colorectal Dis 35(7):1255-1264. https://doi.org/10.1007/ s00384-020-03596-w

24. Park CH, Cheon JH, Kim JO, Shin JE, Jang BI, Shin SJ et al (2011) Criteria for decision making after endoscopic resection of well-differentiated rectal carcinoids with regard to potential lymphatic spread. Endoscopy 43(9):790

25. Kang HS, Kwon MJ, Kim T, Han J, Ju Y (2019) Lymphovascular invasion as a prognostic value in small rectal neuroendocrine tumor treated by local excision: a systematic review and meta-analysis. Pathol Res Pract 215(11):152642. https://doi.org/10.1016/j.prp.2019.152642

26. Yu Y, Li Y, Shi Y, Zhang Z, Zheng M, Zhang S (2020) Clinical and pathological characteristics and prognosis of 132 cases of rectal neuroendocrine tumors. World J Gastro Oncol 12(8):893-902. https://doi.org/10.4251/wjgo.v12.i8.893

27. Kim J, Kim JY, Oh EH, Yoo C, Park IJ, Yang D et al (2020) Chromogranin A expression in rectal neuroendocrine tumors is associated with more aggressive clinical behavior and a poorer prognosis. Am J Surg Pathol 44(11):1496-1505. https://doi.org/ 10.1097/PAS.0000000000001526

28. Shafqat H, Ali S, Salhab M, Olszewski AJ (2015) Survival of patients with neuroendocrine carcinoma of the colon and rectum: a population-based analysis. Dis Colon Rectum 58(3):294-303. https://doi.org/10.1097/DCR.0000000000000298

29. Brodsky JT, Richard GK, Cohen AM, Minsky BD (1992) Variables correlated with the risk of lymph node metastasis in early rectal cancer. Cancer-Am Cancer Soc 69(2):322-326. https://doi.org/10.1002/1097-0142(19920115)69:2<322::aidcncr2820690208>3.0.co;2-b

30. Bosch SL, Teerenstra S, de Wilt JHW, Cunningham C, Nagtegaal ID (2013) Predicting lymph node metastasis in pT1 colorectal cancer: a systematic review of risk factors providing rationale for therapy decisions. Endoscopy 45(10):827

Publisher's Note Springer Nature remains neutral with regard to jurisdictional claims in published maps and institutional affiliations. 